\title{
Significance of CXC chemokine receptor 4 (CXCR4) in Renal Cell Carcinoma
}

\author{
Abd Ellatif El Balshy ${ }^{a}$, Ahlam A. Abd El Maksoud ${ }^{\text {a }}$, Rasha M. El Sawi ${ }^{\text {a }}$, Yara M. Nagieb ${ }^{\text {b }}$
}

a Department of pathology,

Benha faculty of medicine,

Benha University, Egypt.

Benha Fever Hospital, Benha, Egypt

Correspondence to: Yara $\mathrm{M}$. Nagieb, Benha Fever Hospital, Benha, Egypt

Email:

dryaraaiad@gmail.com

Received: 28 September 2020

Accepted: 14 November 2020

\begin{abstract}
:
Background: Cancer stem cells (CSCs) represent a population with tumour initiating, self-renewal, and differentiation potential. The aim of the work is to evaluate the expression patterns and clinical significance of chemokine receptor type 4 (CXCR4) as a novel CSC marker in renal cell carcinoma (RCC). Material and Methods: the expression of CXCR4 was examined in 50 well-defined renal tumour tissues, including 28 clear cell renal cell carcinomas (ccRCCs), 11 papillary renal cell carcinomas (pRCCs), and 11 chromophobe renal cell carcinomas (ChRCCs) with immunohistochemistry staining, the association between expression of this marker and clinicopathologic parameters, was then analyzed. Results: CXCR4 expression \& intensity was significantly correlated with RCC clinicopathological features as grade, stage, size of the tumor and microvascular invasion (MVI) but there was insignificant correlation between histopathological types and the pattern of CXCR4 expression and its intensity .
\end{abstract}

Conclusion: increased CXCR4 expression was associated with more aggressive tumour behaviour in RCC patients, especially in pRCC and ccRCC subtypes due to their more metastatic behaviour. These findings suggest that CXCR4 can be considered as a novel prognostic and therapeutic marker for targeted therapy of renal carcinoma.

Keywords: Cancer stem cells, Renal cell carcinoma, chemokine receptor type 4. 


\section{Introduction}

Renal cell carcinoma (RCC) is a heterogeneous group of cancers arising from renal tubular epithelial cells that encompasses $85 \%$ of all primary renal neoplasms. It is the sixteenth cause of death from cancer in the world, and the most deadly cancer of the urinary tract [1], [2].

Different cancers have different risk factors. Some risk factors can be changed but others, like the age or family history, can't be changed. So that scientists have found several risk factors which increase the chances of developing kidney cancer as lifestyle, smoking, diet and other diseases as DM \& hypertension [3].

Subtyping of renal cell carcinoma (RCC) has become increasingly complicated since the modern WHO, 2016 classification [4].

An accurate knowledge of the individual risk of renal cell carcinoma (RCC) progression and prediction of the individual likelihood of recurrence based on prognostic factors is essential to counsel patients, individual surveillance, and select patients for adjuvant clinical trials. Prognostic factors are subclassified into anatomical, histological, clinical and molecular factors [5].
Grading system is believed to be one of the most imperative prognostic factors in patients with renal cell carcinoma $R C C$. The clinical utility of nuclear grade in combination with other pathologic and clinical factors helps to provide the physician and patient with an indication of prognosis [6[, [7]. Several grading schemes exist for renal cell carcinoma as Fuhrman and World Health Organization /International Society of Urological Pathology WHO/ISUP grading systems, it categories renal cell carcinoma with grades 1, 2, 3, 4 based on nuclear and nucleoli characteristics [8].

The Tumor-Node-Metastasis (TNM) staging system has been recognized globally for decades as the benchmark in staging cancers for cancer classification, prognostication, management, data registry, clinical trials and researches. The American Joint Committee on Cancer (AJCC) published its 8th edition of the AJCC Cancer Staging Manual (8E AJCC) and creates a staging schema that aims to meet both the cancer surveillance and registry needs [9].

In RCC, the 8E AJCC T3 category, clarifications were made in T3a disease classification involving renal vein and its tributaries. T3a criteria in the 7 th edition had 
over reliance on the prosector's gross inspection of the hilar vessels. Modifications in T3a may have impact on clinical trials for adjuvant chemotherapy when defining locally invasive disease [10].

C-X-C chemokine receptor 4 ( CXCR4) belongs to the group of seven transmembrane G-protein coupled chemokine receptors (GPCR), which are peptide mediators involved in normal development, immune \&hematopoietic regulation, inflammation, and wound healing [11]. The ligand for CXCR4 is an alpha chemokine stromal-derived factor (SDF-1) also named (CXCL12). CXCR4/SDF-1 signaling as a chemoattractant pathway for stem cells to home to target tissues axis by activation of multiple $\mathrm{G}$ protein-dependent signaling pathways which play a role in the proliferation, adhesion, chemotaxis and invasion of several tumors as RCC [12], [13]. Cancer stem cells (CSCs) represent a population with tumour initiating, self-renewal, and differentiation potential, and are resistant to chemotherapy and radiation therapy [14], so CXCR4 plays a role in the maintenance and drug-resistant features of CSCs as they are CXCR4-positive, express stem cellassociated transcription factor genes at elevated levels. Research showed that high
CXCR4 expression may affect the chemotherapy drug reaction in metastatic cancers as renal cancer, as it was correlated with a sunitinib poor response for patients with metastatic renal cancer. Patients with negative or low CXCR4 expression were more likely to obtain longer progression-free survival (PFS) [15], [16], [17].

Thus, we conducted the current study to evaluate the expression of CXCR4 marker in different histopathological types of renal cell carcinoma and correlate the findings with the clinical and pathological findings [14].

\section{Material and Methods:}

This study is a retrospective study carried out on 50 formalin fixed paraffin embedded tissue specimens of different types of renal cell carcinoma (clear cell, papillary, and chromophobe), collected from Pathology Department and Early Cancer Detection Unit, Faculty of Medicine, Benha University(2018 \&2019). From each block 4um sections were cut and the slides were subjected to $\mathrm{H} \& \mathrm{E}$ staining and immunohistochemical staining for detection and studying the expression of CXCR4 cancer stem cell marker. Cases were selected on the bases of availability of demographic data as age and sex, and the available clinicopathological data including 
tumour size, microvascular invasion (MVI).

This was approved by ethical committee of Benha Faculty of Medicine

\section{A) Histopathological Study:}

Histologic sections, four microns thick, were stained by Hematoxyline and Eosin $(\mathrm{H} \& \mathrm{E})$ for histopathological study of different types of renal cell carcinoma (clear cell, papillary and chromophobe). The studied H\&E sections were reviewed and were also used to select representative areas of the tumor for subsequent immunohistochemical study. Nuclear grading was done according to Fuhrman grading systems [8]. Staging, clinical and pathologic parameters were evaluated according to TNM staging system of the American Joint Committee on Cancer (AJCC) 8th edition (8E AJCC) [9].

\section{B) Immunohistochemistry :}

Immunohistochemical study was performed to evaluate the expression of the human polyclonal anti- CXCR4 antibody (CD184, Chongqing Biospes Co., Ltd, China) as a novel cancer stem cells marker in renal cell carcinoma cases (clear, papillary, chromophobe) and the control cases (normal kidney and breast carcinoma) as follows:
1-Formalin-fixed paraffin-embedded tissue sections were cut at 3-4 $\mu \mathrm{m}$ and mounted on positively charged glass slides .Then the slides were put in the oven $60^{\circ} \mathrm{C}$ for 30 minutes. Non-representative areas of the tumor were scraped off the slide.

2-Slides were deparaffinized in two xylene jars for 15-20 minutes for each and rehydrated through graded series of ethanol $(100 \%-95 \%-70 \%) 5$ minutes for each.

3-Slides were washed with distilled water 3 times for 5 minutes each.

4-Slides rack placed in two Coplan jar containing phosphate buffer saline (PBS) (pH 7.4) for 5 minutes.

5-Blocking endogenous peroxidase activity was done by immersing the slides in $3 \%$ hydrogen peroxide in $30 \%$ methanol for 10 minutes, then sections were rinsed in (PBS) for 5 minutes.

6-Slides were microwaved in a microwave oven (General Electric,1000 Watts) for 15 20 minutes. Amount of fluid in the Coplan jar was checked and water was added if necessary to prevent slides from drying out.

7-The jar was removed from the oven and allowed to cool for 20 minutes. 
8-Slides were then washed in distilled water several times then placed in phosphate buffer saline (PBS) (pH 7.4) for 5 minutes.

9-Slides were placed in Altra D block for 5 minutes.

10-One to two drops of CXCR4 at a dilution of 1:150 were put on each section. Slides were incubated horizontally at the room temperature overnight. The sections were then rinsed in BPS.

11-Each section was incubated for 10 minutes with biotinylated second antibody, and then the sections were rinsed in PBS.

12-Slides were incubated for 10 minutes with streptavidin- horseradish peroxidase solution, and then sections were rinsed in PBS.

13-Freshly prepared DAB solution (chromogen diaminobenzidine and dap substrate) was used; it was incubated with slides for 1-3 minutes.

14-Slides were then washed in distilled water then counterstained for 3 minutes with Meyer's Hematoxylin.

15-Slides were rehydrated through graded series of ethanol $\left(\begin{array}{llll}70 \% & -95 \% & -100 \%) & 1\end{array}\right.$ minutes for eash.
16-Slides were deparaffinized in xylene for 15 minutes.

17-A drop of DPX mountant was added and sections were covered by a glass cover.

18-Normal renal tissue and breast carcinoma was used as a positive control.

\section{Evaluation of CXCR4 immunostaining:}

Slides were scanned at $10 \times$ magnification to obtain a general impression of the overall distribution of the tumour cells, and positive cells were then assessed at higher magnifications $40 \times$ and final scores were given. The degree of staining was categorized based on the severity of staining with a comparative scale. The intensity of the CXCR4 immunostaining was scored on a scale of $0-3$, with a score of $(0=$ no visible staining, $1=$ weak staining, $2=$ moderate staining, and $3=$ strong staining). The percentage of tumour cells with positive staining was graded as $(<25: 1$, 25-50:2, 50-75:3 and >75\%:4). To compare all of the available data, an overall histochemical score ( $\mathrm{H}$ score) was assigned to each case by multiplying the intensity score by the percentage of stained cells, and a final score of (0-300) was given. A cutoff point of 200 was chosen based on the median $\mathrm{H}$ score to categorize samples as high or low CXCR4 expression [14]. 
Analysis of IHC staining demonstrated that expression of CXCR4 was localized to (cell membrane and cytoplasm) of the tumor cells and (cytoplasmic and nuclear) of the other cells [23], [24],[29].

\section{Statistical analysis:}

Statistical software SPSS version 16 9Chicago, Illo, USA) was used for data feeding and analysis. For quantitative variables mean with standard deviation was calculated. For qualitative categorical variables percentages and frequencies were calculated. CXCR4 expression and clinicopathological parameters were determined. $\mathrm{P}$ value $<0.05$ was considered significant and $\mathrm{P}$ value $<0.001$ was considered highly significant.

\section{Result:}

Demographic and clinicopathological features: Among 50 studied cases, 28 cases (56\%) clear cell RCC, 11 cases (22\%) papillary RCC, and 11 cases $(22 \%)$ chromophobe RCC parallel to this study, they found that clear cell RCC was the most common type but papillary and chromophobe were less common, 35 (70\%) of all cases are male and $15(30 \%)$ of them are female. There is a clear predominance of men among patients with RCC.Cases of
RCC were classified into 2 groups, group I $\leq$ 56 years old and group II >56 years old. The mean age of the population in this study is 59 years (range 46-70). There was insignificant correlation between histopathological types and the age, $\mathrm{P}$ value $>0.05$, but there was a statistically significant between the grade, stage and the age $\mathrm{P}$ value $<0.001$.

Out of clear and papillary cases, 5 cases $(12.8 \%)$ were grade 1,15 cases $(38.5 \%)$ were grade 2,18 cases $(46.2 \%)$ were grade 3 and 1case $(2.6 \%)$ were grade 4 . There was insignificant correlation between histopathological types and grades, $\mathrm{P}$ value $>0.05$, patients with clear cell and papillary RCC. Out of 50 studied cases, 22 cases (44\%) were stage I, 14 cases (28\%) were stage II and 14 cases (28\%) were stage III. A similar correlation was found with TNM staging, $\mathrm{P}$ value $>0.05$.

Tumour size was categorized into four groups: $\leq 4,4-7,7-10$, and $\geq 10 \mathrm{~cm}$. The median tumour size was $10 \mathrm{~cm}$, the mean size (range $1-21 \mathrm{~cm}$ ). There was a statistically significant between the types, grade, stage and the size $\mathrm{P}$ value $<0.001$. Pattern of CXCR4 expression, intensity and $\mathrm{H}$ score results: (Tables 1 to 5), (Figures 1to 8) 
Benha medical journal vol.38, academic issue, 2021

Our findings suggest $\mathrm{H}$ score was found with tumor size and stage, $\mathrm{P}$ value < significantly correlated with higher grade 0.001. There was insignificant correlation tumor and microvascular invasion, $\mathrm{P}$ value $<$ 0.05. Highly significant association was also between histopathological types and $\mathrm{H}$ score, $\mathrm{P}$ value $>0.05$.

Table 1: correlation between RCC types and CXCR4 expression:

\begin{tabular}{llll}
\hline Types & Papillary (11) & Clear (28) & Chromophobe (11) \\
\hline
\end{tabular}

$\mathrm{M}+\mathrm{C}(\mathrm{CXCR} 4)$

Scores

$\begin{array}{lllllll}<25 \% & 3 & 27.3 & 6 & 21.4 & 4 & 36.4 \\ 25 \%- & 4 & 36.4 & 9 & 32.1 & 5 & 45.5 \\ 50-75 \% & 4 & 36.4 & 9 & 32.1 & 1 & 9.1 \\ >75 \% & 0 & 0.0 & 4 & 14.3 & 1 & 9.1\end{array}$

C+N (CXCR4)

Scores

$\begin{array}{lllllll}<25 \% & 6 & 54.5 & 13 & 46.4 & 9 & 81.8 \\ 25 \%- & 2 & 18.2 & 10 & 35.7 & 2 & 18.2 \\ >75 \% & 3 & 27.3 & 5 & 17.9 & 0 & 0.0\end{array}$

Intensity

$\begin{array}{lllllll}\text { Weak } & 3 & 27.3 & 9 & 32.1 & 5 & 45.5 \\ \text { Intermediate } & 3 & 27.3 & 7 & 25.0 & 5 & 45.5 \\ \text { Strong } & 5 & 45.5 & 12 & 42.9 & 1 & 9.1\end{array}$

H1 score

\begin{tabular}{lllllll}
$\leq 200$ & 11 & 100 & 21 & 75.0 & 10 & 90.9 \\
$>200$ & 0 & 0.0 & 7 & 25.0 & 1 & 9.1 \\
H2 score & & & & & & \\
$\leq 200$ & 8 & 72.7 & 23 & 82.1 & 11 & 100 \\
$>200$ & 3 & 27.3 & 5 & 17.9 & 0 & 0.0 \\
\hline
\end{tabular}


Benha medical journal vol.38, academic issue, 2021

Table 2: correlation between the grade and CXCR4 expression:

\begin{tabular}{lllll}
\hline Furhman grades & Grade I (5) & Grade II (15) & Grade III (18) & Grade IV (1)
\end{tabular}

M+C (CXCR4)

Scores

$\begin{array}{lllllllll}<25 \% & 5 & 100 & 4 & 26.7 & 0 & 0.0 & 0 & 0.0 \\ 25 \%- & 0 & 0.0 & 8 & 53.3 & 5 & 27.8 & 0 & 0.0 \\ 50-75 \% & 0 & 0.0 & 3 & 20.0 & 9 & 50.0 & 1 & 50.0 \\ >75 \% & 0 & 0.0 & 0 & 0.0 & 4 & 22.2 & 1 & 50.0\end{array}$

\section{C+N (CXCR4)}

\section{Scores}

$\begin{array}{lllllllll}<25 \% & 5 & 100 & 13 & 86.7 & 1 & 5.6 & 0 & 0.0 \\ 25 \%- & 0 & 0.0 & 2 & 13.3 & 10 & 55.6 & 0 & 0.0 \\ >75 \% & 0 & 0.0 & 0 & 0.0 & 7 & 38.9 & 1 & 100\end{array}$

Intensity

$\begin{array}{lcccccccc}\text { Weak } & 5 & 100 & 7 & 46.7 & 0 & 0.0 & 0 & 0.0 \\ \text { Intermediate } & 0 & 0.0 & 8 & 53.3 & 2 & 11.1 & 0 & 0.0 \\ \text { Strong } & 0 & 0.0 & 0 & 0.0 & 16 & 88.9 & 1 & 100\end{array}$

H1 score

\begin{tabular}{lllllllll}
$\leq 200$ & 5 & 100 & 15 & 100 & 11 & 61.1 & 1 & 100 \\
$>200$ & 0 & 0.0 & 0 & 0.0 & 7 & 38.9 & 0 & 0.0 \\
H2 score & & & & & & & & \\
$\leq 200$ & 5 & 100 & 15 & 100 & 11 & 61.1 & 0 & 0.0 \\
$>200$ & 0 & 0.0 & 0 & 0.0 & 7 & 38.9 & 1 & 100 \\
\hline
\end{tabular}


Table 3: correlation between the stage and CXCR4 expression:

\begin{tabular}{|c|c|c|c|c|c|c|}
\hline \multirow{2}{*}{$\begin{array}{l}\text { Stages } \\
\mathrm{M}+\mathrm{C}(\mathrm{CXCR}\end{array}$} & \multicolumn{2}{|c|}{ Stage I (22) } & \multicolumn{2}{|c|}{ Stage II (14) } & \multicolumn{2}{|c|}{ Stage III (14) } \\
\hline & & & & & & \\
\hline \multicolumn{7}{|l|}{ Scores } \\
\hline$<25 \%$ & 13 & 59.1 & 0 & 0.0 & 0 & 0.0 \\
\hline $25 \%-$ & 9 & 40.9 & 4 & 28.6 & 5 & 35.7 \\
\hline $50-75 \%$ & 0 & 0.0 & 10 & 71.4 & 4 & 28.6 \\
\hline$>75 \%$ & 0 & 0.0 & 0 & 0.0 & 5 & 35.7 \\
\hline \multicolumn{7}{|c|}{$\mathrm{C}+\mathrm{N}(\mathrm{CXCR4})$} \\
\hline \multicolumn{7}{|l|}{ Scores } \\
\hline$<25 \%$ & 22 & 100 & 6 & 42.9 & 0 & 0.0 \\
\hline $25 \%-$ & 0 & 0.0 & 8 & 57.1 & 6 & 42.9 \\
\hline$>75 \%$ & 0 & 0.0 & 0 & 0.0 & 8 & 57.1 \\
\hline \multicolumn{7}{|l|}{ Intensity } \\
\hline Weak & 17 & 77.3 & 0 & 0.0 & 0 & 0.0 \\
\hline Intermediate & 5 & 22.7 & 10 & 71.4 & 0 & 0.0 \\
\hline Strong & 0 & 0.0 & 4 & 28.6 & 14 & 100 \\
\hline \multicolumn{7}{|l|}{ H1 score } \\
\hline$\leq 200$ & 22 & 100 & 12 & 85.7 & 8 & 57.1 \\
\hline$>200$ & 0 & 0.0 & 2 & 14.3 & 6 & 42.9 \\
\hline \multicolumn{7}{|l|}{ H2 score } \\
\hline$\leq 200$ & 22 & 100 & 14 & 100 & 6 & 42.9 \\
\hline$>200$ & 0 & 0.0 & 0 & 0.0 & 8 & 57.1 \\
\hline
\end{tabular}


Benha medical journal vol.38, academic issue, 2021

Table 4: correlation between tumor size and CXCR4 expression

\begin{tabular}{|c|c|c|c|c|c|c|c|c|}
\hline \multirow[b]{2}{*}{$\mathrm{M}+\mathrm{C}(\mathrm{CXCR} 4)$} & \multicolumn{2}{|c|}{ Group I (9) } & \multicolumn{2}{|c|}{ Group II (14) } & \multicolumn{2}{|c|}{ Group III (12) } & \multicolumn{2}{|c|}{ Group IV (15) } \\
\hline & & & & & & & & \\
\hline \multicolumn{9}{|l|}{ Scores } \\
\hline$<25 \%$ & 9 & 100 & 4 & 28.6 & 0 & 0.0 & 0 & 0.0 \\
\hline $25 \%-$ & 0 & 0.0 & 10 & 71.4 & 4 & 33.3 & 4 & 26.7 \\
\hline $50-75 \%$ & 0 & 0.0 & 0 & 0.0 & 7 & 58.3 & 7 & 46.7 \\
\hline$>75 \%$ & 0 & 0.0 & 0 & 0.0 & 1 & 8.3 & 4 & 26.7 \\
\hline \multicolumn{9}{|c|}{$\mathrm{C}+\mathrm{N}(\mathrm{CXCR} 4)$} \\
\hline \multicolumn{9}{|l|}{ Scores } \\
\hline$<25 \%$ & 9 & 100 & 14 & 100 & 5 & 41.7 & 0 & 0.0 \\
\hline $25 \%-$ & 0 & 0.0 & 0 & 0.0 & 6 & 50.0 & 8 & 53.3 \\
\hline$>75 \%$ & 0 & 0.0 & 0 & 0.0 & 1 & 8.3 & 7 & 46.7 \\
\hline \multicolumn{9}{|l|}{ Intensity } \\
\hline Weak & 9 & 100 & 8 & 57.1 & 0 & 0.0 & 0 & 0.0 \\
\hline Intermediate & 0 & 0.0 & 6 & 42.9 & 8 & 66.7 & 1 & 6.7 \\
\hline Strong & 0 & 0.0 & 0 & 0.0 & 4 & 33.3 & 14 & 93.3 \\
\hline \multicolumn{9}{|l|}{ H1 score } \\
\hline$\leq \mathbf{2 0 0}$ & 9 & 100 & 14 & 100 & 11 & 91.7 & 8 & 53.3 \\
\hline$>200$ & 0 & 0.0 & 0 & 0.0 & 1 & 8.3 & 7 & 46.7 \\
\hline \multicolumn{9}{|l|}{ H2 score } \\
\hline$\leq \mathbf{2 0 0}$ & 9 & 100 & 14 & 100 & 11 & 91.7 & 8 & 53.3 \\
\hline$>200$ & 0 & 0.0 & 0 & 0.0 & 1 & 8.3 & 7 & 46.7 \\
\hline
\end{tabular}


Table 5: correlation between MVI and CXCR4 expression

\begin{tabular}{|c|c|c|c|c|}
\hline \multirow{2}{*}{$\frac{\text { MVI }}{M+C(C X C R 4}$} & \multicolumn{2}{|c|}{ Positive (33) } & \multicolumn{2}{|c|}{ Negative (17) } \\
\hline & & & & \\
\hline \multicolumn{5}{|l|}{ Scores } \\
\hline$<25 \%$ & 3 & 9.1 & 10 & 58.8 \\
\hline $25 \%-$ & 11 & 33.3 & 7 & 41.2 \\
\hline $50-75 \%$ & 14 & 42.4 & 0 & 0.0 \\
\hline$>75 \%$ & 5 & 15.2 & 0 & 0.0 \\
\hline \multicolumn{5}{|c|}{$\mathrm{C}+\mathrm{N}(\mathrm{CXCR4})$} \\
\hline \multicolumn{5}{|l|}{ Scores } \\
\hline$<25 \%$ & 11 & 33.3 & 17 & 100 \\
\hline $25 \%-$ & 14 & 42.4 & 0 & 0.0 \\
\hline$>75 \%$ & 8 & 24.2 & 0 & 0.0 \\
\hline \multicolumn{5}{|l|}{ Intensity } \\
\hline Weak & 4 & 12.1 & 13 & 76.5 \\
\hline Intermediate & 11 & 33.3 & 4 & 23.5 \\
\hline Strong & 18 & 54.5 & 0 & 0.0 \\
\hline \multicolumn{5}{|l|}{ H1 score } \\
\hline$\leq 200$ & 25 & 75.8 & 17 & 100 \\
\hline$>200$ & 8 & 24.2 & 0 & 0.0 \\
\hline \multicolumn{5}{|l|}{ H2 score } \\
\hline$\leq 200$ & 25 & 75.8 & 17 & 100 \\
\hline$>200$ & 8 & 24.2 & 0 & 0.0 \\
\hline
\end{tabular}

$\mathrm{C}+\mathrm{M}=$ Cytoplasm + cell membrane $\quad \mathrm{C}+\mathrm{N}=$ Cytoplasm + Nucleus

H1: $(\mathrm{C}+\mathrm{m}) \% \mathrm{x}$ intensity score $\mathrm{H} 2:(\mathrm{C}+\mathrm{n}) \% \mathrm{x}$ intensity score 
Benha medical journal vol.38, academic issue, 2021

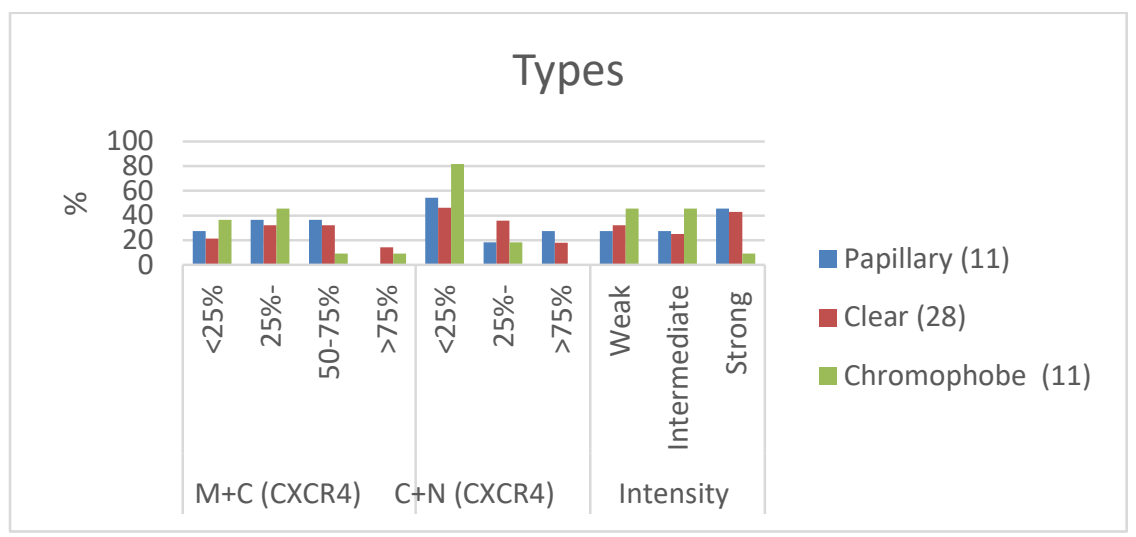

Figure 1: CXCR4 \& Types

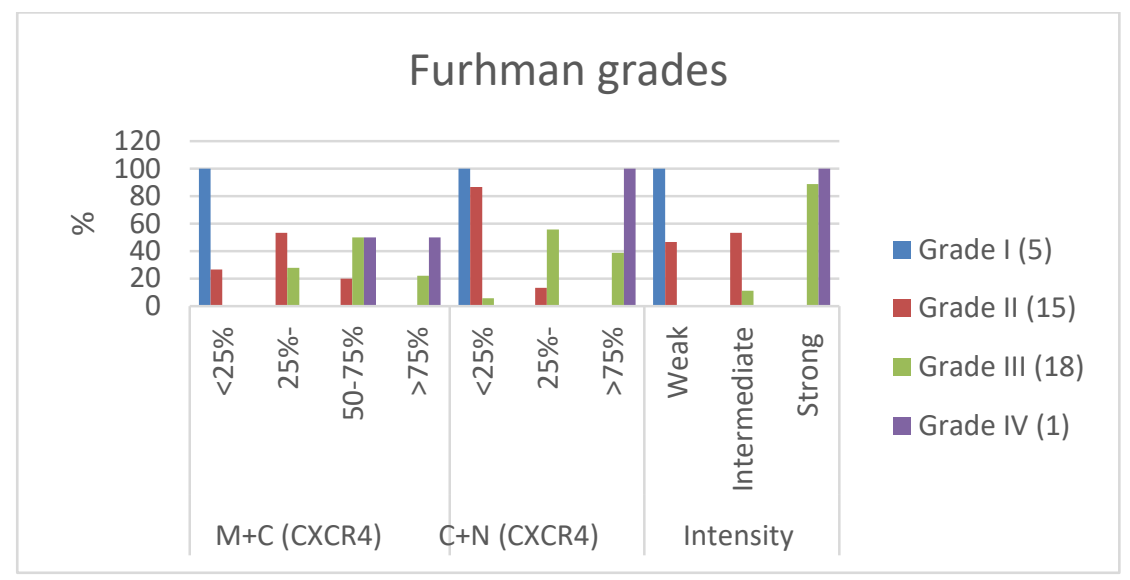

Figure 2: CXCR4 \& Grade

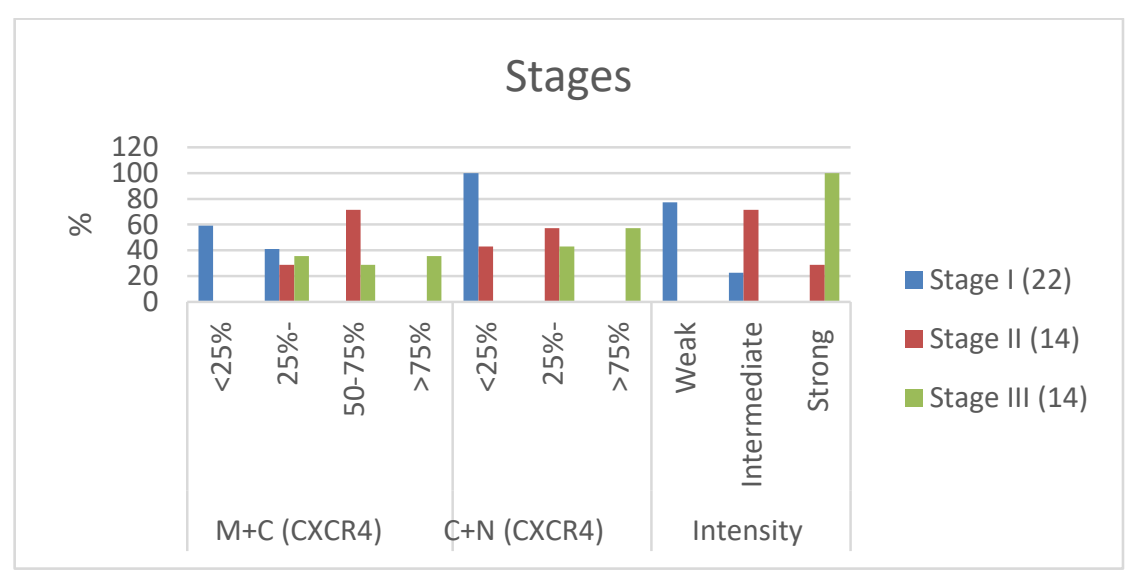

Figure 3: CXCR4 \& Stage 


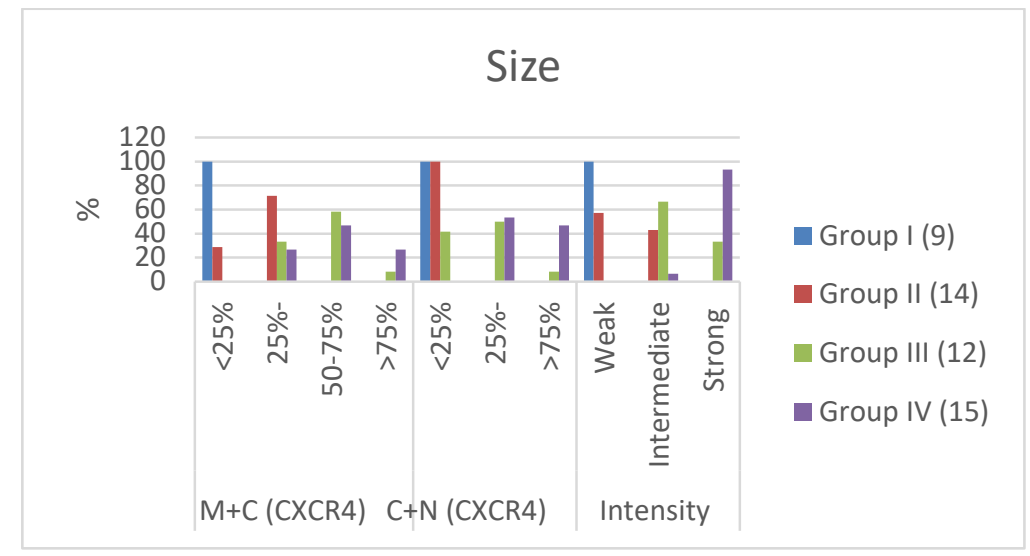

Figure 4: CXCR4 \& The size

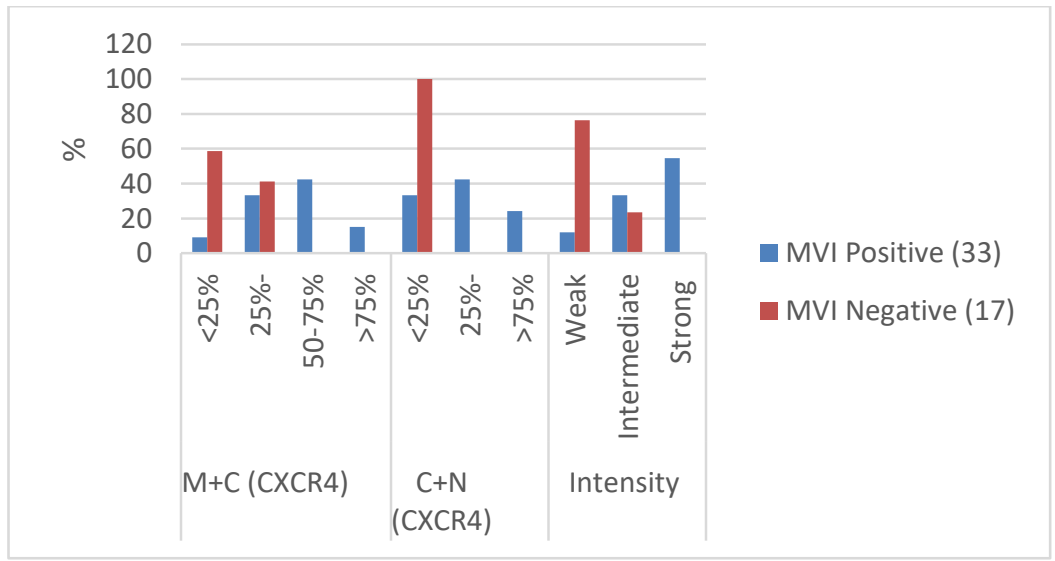

Figure 5: CXCR4 \& MVI
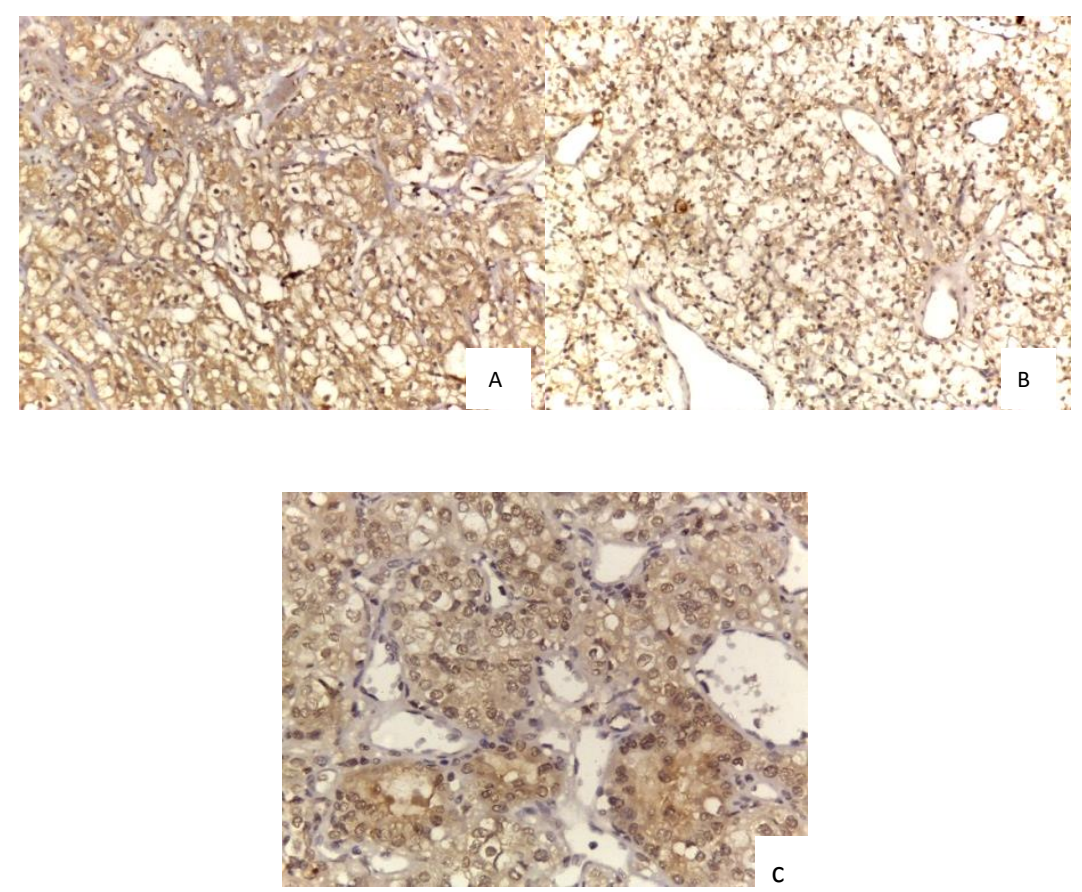

(Figure 6): Clear cell RCC showing weak membranous CXCR4 expression (CXCR4 x10) (A), intermediate membranous and cytoplasmic CXCR4 expression (CXCR4 x10) (B), strong cytoplasmic and nuclear CXCR4 expression (CXCR4 x10) (C). 


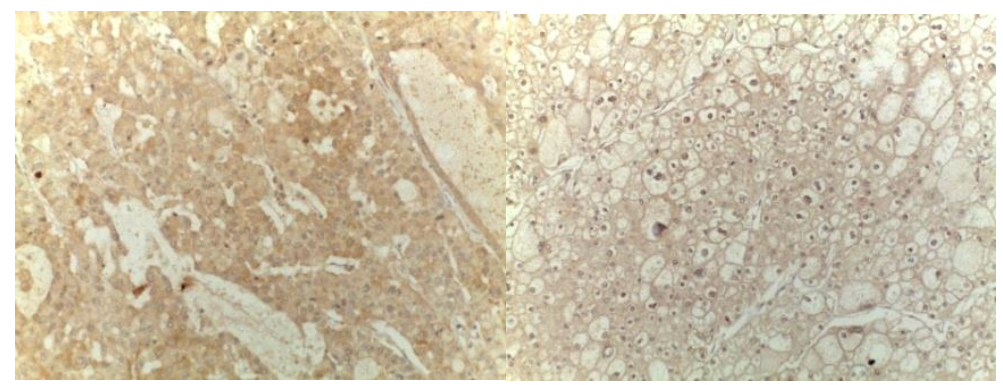

A

B

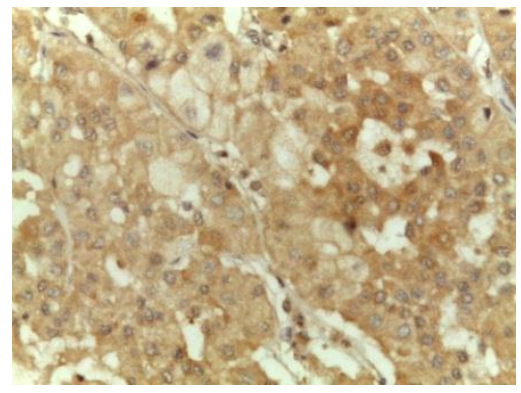

C

(Figure 7): Chromophobe cell RCC showing weak membranous and cytoplasmic CXCR4 expression, (CXCR4 x10) (A), intermediate membranous and cytoplasmic CXCR4 expression, (CXCR4 x10) (B) strong membranous and cytoplasmic CXCR4 expression, (CXCR4 x40)(C).

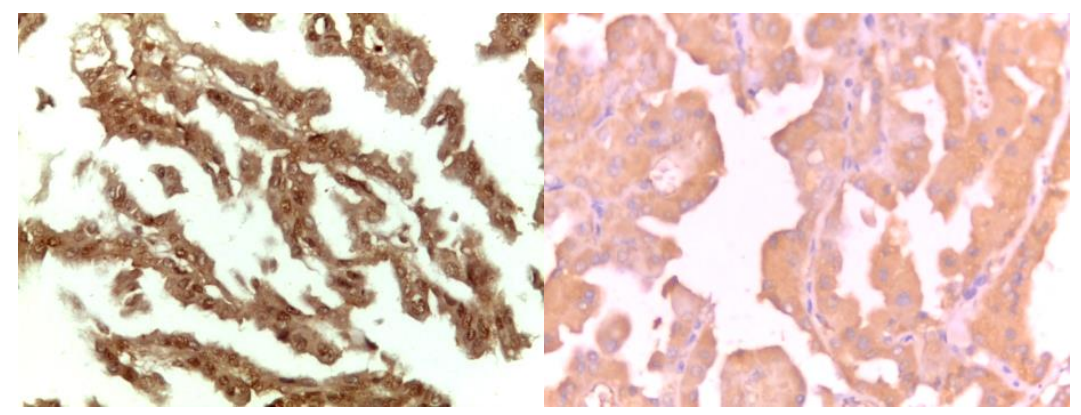

A

B

(Figure 8): Papillary cell RCC : showing membranous and cytoplasmic CXCR4 expression (CXCR4 x10) (A), cytoplasmic and nuclear CXCR4 expression (CXCR4 x40) (B).

\section{Discussion:}

C-X-C chemokine receptor 4 (CXCR4) belongs to the group of seven transmembrane G-protein coupled chemokine receptors (GPCR).
Chemokines are peptide mediators involved in normal development, immune and hematopoietic regulation, inflammation, and wound healing [11]. 
CXCR4 appears to be the major chemokine receptor expressed on cancer cells. It was found in more than 20 types of tumors in human as prostate, ovarian and esophageal cancer and melanoma. It is always slowly expressed in normal tissues [18], [19].

The ligand for CXCR4 is an alpha chemokine stromal derived factor (SDF-1) also named (CXCL12). CXCR4/CXCL12 axis plays an important role in activation of a variety of biological processes such as stemness, survival, proliferation, migration, angiogenesis, differentiation and regulating metastasis of $\mathrm{CXCR} 4$ positive tumor cells to the organs expressing CXCL12 [12], [28].

Studies have shown that CXCR4 expression determine prognosis for many types of tumors as lung, ovarian and colorectal cancer. The prognostic prediction CXCR4 was different, even opposite in them. Nuclear CXCR4 expression was associated with a favorable prognosis in non-small cell lung cancer but a poor prognosis in primary colon cancer and ovarian cancer [20], [21], [22], [29].

CXCR4 plays a good role also in the maintenance and drug-resistant features of cancer stem cells CSCs as they are CXCR4-positive, express stem cellassociated transcription factor genes at elevated levels. Patients with negative or low CXCR4 expression were more likely to obtain longer progression-free survival (PFS) [14], [15], [16], [17].

Concerning the pattern of CXCR4 expression in the control cases as normal kidney showed brownish cytomembranous staining of the tubules and the breast carcinoma showed brownish cytoplasmic staining [18], [25], [27].

In our study, CXCR4 is predominantly localized in the cytoplasm and in the membrane of the primary renal cell carcinoma cells, but mainly in the cytoplasm and the nucleus with the renal cell carcinoma progression and metastases similar to our result [23], [24], [29] but in contrast to [14] who found that expression of CXCR4 was mainly localized to the cytoplasm of tumor cells, nuclear and membrane staining of CXCR4 were not observed.

The level of expression was examined by three scoring methods, the intensity of the staining (weak, intermediate, strong), the percentage of $\mathrm{CXCR} 4$ positive tumor cells (1-2-3-4) score and (H score) was assigned to each case by multiplying the intensity score by the percentage of stained cells, and a final score of 0-300 was given [14]. 
There was insignificant correlation between histopathological types and $\mathrm{H}$ score, $\mathrm{P}$ value $>0.05$. In contrast to these results [14] who found a significant difference in the expression levels of CXCR4 in the ccRCC samples compared to the ChRCC and pRCC samples $\mathrm{P}<0.05$ and higher expression of CXCR4 was associated with poor prognosis in $\mathrm{pRCC}$ and ccRCC samples and increased potential to develop metastasis compared to ChRCC.

In our study, $\mathrm{H}$ score of CXCR4 was significantly correlated with RCC clinicopathological features as:

- There was a statistically significant between grades and $\mathrm{H}$ score of clear cell RCC, P value <0.05. A similar statistically significant was found with papillary cell RCC grade, $\mathrm{P}$ value $<0.05$.

- Highly significant relationship between $\mathrm{H}$ score and tumour stage was observed, $\mathrm{P}$ value $<0.001$.

- Among our RCC samples, a significant association was found also between $\mathrm{H}$ score and microvascular invasion MVI, especially in ccRCC samples. Recent studies have reported that MVI has more influence on prognosis after surgical treatment compared to macroscopic renal vein or vena cava invasion, $\mathrm{P}$ value $<0.05$.

- In addition, $\mathrm{H}$ score and tumor size was highly positively correlated, $\mathrm{P}$ value $<0.001$.

This was in agreement with [14] who found that, $\mathrm{H}$ score of CXCR4 expression levels was significantly correlated with the RCC clinicpathological features.

These results agreed also with [18], [29] who found that, CXCR4 nuclear localization in primary RCC tissues was correlated with poor prognosis and predicts more metastasis.

And agreed with [23] who found that, renal cell carcinoma progression were associated with higher levels of CXCR4 expression.CXCR4 is predominantly localized in the cytoplasmic and membranous in the primary renal cell carcinoma cells, but mainly in the cytoplasm and the nucleus with the renal cell carcinoma progression and metastases.

While this was disagreed with [19], [26] whose study revealed that, CXCR4 is not associated with other clinical and pathological prognostic factors, except for Fuhrman grading. 
It was found that, CXCR4 is not associated with clinical and pathological factors of RCC [24]

\section{Conclusions:}

Significance of CXCR4 expression in detection the higher grade and the advanced stage of RCC tumor especially ccRCC, pcRCC, chRCC.

Expression of CXCR4 confers tumor progression \& aggressiveness in RCC patients and this is essential to counsel patients, individualize surveillance, select patients for adjuvant clinical trials and maintain drug resistant features of cancer stem cells CSCs.

\section{References:}

1. Mahdavifar N, Ghoncheh M, Pakzad R, Momenimovahed Z, Salehiniya H. Epidemiology, incidence and mortality of bladder cancer and their relationship with thedevelopment index in the world. Asian Pac J Cancer Prev 17: 381-386, 2016.

2. Hsieh JJ, Purdue MP, Signoretti S, Swanton C, Albiges L, Schmidinger M, et al. Renal cell carcinoma. Nat Rev Dis Primers.; 3: $17009,2017$.

3. American Cancer Society. Cancer Facts \& Figures 2017. Atlanta, Ga: American Cancer Society,2017.

4. WHO, World Health Orgnization. Classification of Tumors of the Urinary System and Male Genital Organs,part A, 2016.
5. Bex A, Albiges L, Ljungberg B, Bensalah K, Dabestani S, Giles RH, et al. Updated European Association of Urology guidelines regarding adjuvant therapy for renal cell carcinoma. EurUrol 71:719-722, 2017.

6. Serrano M F, Katz M , Yan Y , Kibel A S , Humphrey P A . Percentage of high-grade carcinoma as a prognostic indicator in patients with renal cell carcinoma. Published ,doi.org/10.1002/cncr .23574, 16 May 2008.

7. Rini, Brian I, Campbell, Steven C, Escudier, Bernard."Renal cell carcinoma". The Lancet. 373 (9669): 1119-1132, 2009.

8. Kim $\mathrm{H}$, Inomoto $\mathrm{C}$, Furuya $\mathrm{H}$, Komiyama T, Kajiwara H, Kobayashi H, et al. Verification of the International Society of Urological Pathology recommendations in Japanese patients with clear cell renal cell carcinoma.Int J Oncol. Apr; 52(4): 1139-1148.Published online $2018 \quad$ Feb 28. doi: 10.3892/ijo.2018.4294, 2018.

9. Amin, M.B., Edge, S.B., Greene, F.L., et al. AJCC Cancer Staging Manual. ed. 8. Springer, Cham, Switzerland, 2017.

10. Paner, G.P., Stadler, W.M., Hansel, D.E., et al. Updates in the eighth edition of the tumornode-metastasis staging classification for urologic cancers.April ,volume 73, Issue 4, pages 560-569, 2018.

11. Richard C.L. and Blay J. "CXCR4 in cancer and its regulation by PPAR $\gamma$," PPAR Research, vol., Article ID 769413, 19 pages, 2008.

12. Yuefeng Du, Long $Q$, Guan B, and Lijun $\mathrm{Mu}$. Prognostic Value of High CXCR4 Expression in Renal Cell Carcinoma: A System Review and Meta-Analysis Department of Urology, 
First Affiliated Hospital of Medical School, Xi'an Jiaotong University, Xi'an, Shaanxi, China .Correspondence should be addressed to Yuefeng Du .Received 21 June 2015; Revised 1 September 2015; Accepted 2 September 2015.

13. Wu M, Chen Q, Li D, Li X, Tang Y, Huang C, et al. LRRC4 inhibits human glioblastoma cells proliferation, invasion, and proMMP-2 activation by reducing SDF-1 alpha/CXCR4mediated ERK1/2 and Akt signaling pathways. J Cell Biochem 103: 245-255, 2008.

14. Rasti A, Abolhasani M, Zanjani LS , Asgari M , Mehrazma M , Madjd Z. Reduced expression of CXCR4, a novel renal cancer stem cell marker, is associated with high-grade renal cell carcinoma Journal of Cancer Research and Clinical Oncology January, Volume 143, Issue 1, pp 95-104, 2017.

15. Guo J, Tang B, Sheng X N, and Cui C L. "Use of CXCR4 expression to predict the efficacy of sorafenib treatment in patients withmetastatic renal cell carcinoma," Journal of Clinical Oncology, vol. 29, no. 7, pp. 359-364, 2011.

16. D'Alterio C, Portella L, Ottaiano A, Rizzo M, Carteni G, Pignata $\mathrm{S}$, et al., "High CXCR4 expression correlates with sunitinib poor response inmetastatic renal cancer," Current Cancer Drug Targets, vol. 12, no. 6, pp.693702, 2012.

17. Gassenmaier M, Chen D, Buchner A, Henkel L, Schiemann M, Mack B, et al . CXC chemokine receptor 4 is essential for maintenance of renal cell carcinoma-initiating cells and predicts metastasis. Stem Cells 31:1467-1476, 2013.
18. Xu Z, Li P, Wei D, Wang Z, Bao Y, Sun J, et al. NMMHC-IIA-dependent nuclear location of CXCR4 promotes migration and invasion in renal cell carcinoma. Doi.org/10.3892/or. 2016.5082. Pages: 2681-2688. Published online on: September 12, 2016.

19. Li X, Huang Y, Xia J, Chen N, Wei Q, Li X, et al. "Cxcr4 expression in patients with high-risk locally advanced renal cell carcinoma can independently predict increased risk of disease progression and poor overall survival, "Asian Pacific Journal of Cancer Prevention, 12, pp. 3313-3318, 2011.

20. Speetjens FM, Liefers GJ, Korbee CJ, Mesker WE, Morreau H, Tollenaar RA, et al. Nuclear localization of CXCR4 determines prognosis for colorectal cancer patients. Cancer Microenviron. 2:1-7. 2009.

21. Liu C F, Liu S Y, Min X Y, Ji YY, Wang N, Liu D, et al. "The prognostic value of CXCR4 in ovarian cancer: a meta-analysis," PLoS ONE, vol. 9, no. 3, Article IDe92629, 2014.

22. Wang L, Chen W, Gao L, Yang Q, Liu B, Wu Z, et al. High expression of CXCR4, CXCR7 and SDF-1 predicts poor survival in renal cell carcinoma. World J Surg Oncol. 10:212. 2012.

23. Wang L, Yang B , Yang Q, Qiao S, Wang Y, Sun Y, et al. Strong expression of chemokine receptor CXCR4 by renal cell carcinoma cells correlates with metastasis Received: 29 July 2009 / Accepted: 9 October 2009 / Published online: 27 October $\quad-\quad$ Springer Science+Business Media B.V. 2009.

24. Chen $\mathrm{W}$, Wang L, Gao L, Yang Q, Liu B, Wu Z, et al. High expression of CXCR4, CXCR7 and SDF-1 predicts poor survival in renal cell 
Benha medical journal vol.38, academic issue, 2021

carcinoma. Accepted: 26 September 2012.

Published: 7 October 2012.

25. Derlin $T$ and Hueper $K$. CXCR4 target therapy in breast carcinoma . Puplished : August, 2018, doll. org/ 10.1016 / S1470-2045(18)30480-7, 2018.

26. Tang B, Tang F, Li Y, Yuan S, Li B, Wang Z, et al. Clinicopathological significance of CXCR4 expression in renal cell carcinoma: a meta-analysis. Ann Surg Oncol. 2015.

27. Graf C, Wehler TC, Biesterfeld S, Brenner W, Schadt J, Gockel I, et al. Strong Expression of Chemokine Receptor CXCR4 by Renal Cell Carcinoma Correlates with Advanced Disease. DOI: $10.1155 / 2008 / 626340$ - Source: PubMed
. in Journal of Oncology 2008(2):626340 - Dec, 2008.

28. Schaefer B, Moch H, Bodenmiller B, Frew L, Rechsteiner M. Dissecting Tumor Heterogeneity and Cancer Stem Cell Properties in Clear Cell Renal Cell Carcinoma. Posted at the Zurich Open Repository and Archive, University of Zurich ZORA URL: https://doi.org/10.5167/uzh-150525, 2018.

29. Bao Y, Wang Z, Liu B, Lu X, Xiong Y, Shi J, et al. A feed-forward loop between nuclear translocation of CXCR4 and HIF-1 $\alpha$ promotes renal cell carcinoma metastasis. Oncogene volume 38, pages 881-895, 2019.

To cite this article: Abd E. El Balshy, Ahlam A. Abd El Maksoud, Rasha M. El Sawi, Yara M. Nagieb. Significance of CXC chemokine receptor 4 (CXCR4) in Renal Cell Carcinoma. BMFJ 2021; 38 (academic issue):73-91. DOI: 10.21608/bmfj.2020.17434.1077 